\title{
PEMANFAATAN CELEMEK SEBAGAI MEDIA PEMBELAJARAN SISTEM PENCERNAAN MANUSIA
}

\author{
Mashuri $^{1}$ \\ Guru IPA MTs. Muhammadiyah 1 Malang \\ E-mail : umminetz@gmail.com ${ }^{1}$
}

\begin{abstract}
Abstrak
Media merupakan bagian yang integral dari keseluruhan situasi mengajar, sehingga media merupakan salah satu unsur yang harus dikembangkan guru untuk membantu mempertinggi mutu belajar mengajar. Media pembelajaran sistem pencernaan manusia, selama ini lebih banyak berupa gambar, video flash, power point, dan torso. Kendala yang sering dikeluhkan oleh guru adalah minimnya kemampuan mereka dalam teknologi informasi misalnya penggunaan komputer. Salah satu alternatif dalam pembuatan media belajar, yaitu dengan memanfaatkan barang bekas. Contohnya celemek yang terbuat dari banner bekas menjadi media pembelajaran organ pncernaan manusia yang sederhana, mudah dan murah. Penggunaan media celemek sistem pencernaan makanan, terbukti memberikan efek meningkatkan hasil belajar siswa, yaitu sebesar 95,45\% (21 orang) dari 22 siswa.
\end{abstract}

Kata kunci : celemek, media pembelajaran, hasil belajar

\begin{abstract}
Media is an integral part of overall learning, memorandum media which is one element that must be developed to help. Human system learning media, all this time including more images, video flash, power points, and torso. The obstacle that is often complained by teachers is their lack of ability in information technology and computer use. One alternative in making learning media, namely by utilizing used goods. Examples of aprons made from used banners are simple, easy and inexpensive learning media for human washing organs. The use of food digestive system apron media, proved to improve student learning outcomes, which amounted to $95.45 \%$ (21 people) of 22 students
\end{abstract}

Keywords: aprons, learning media, learning outcomes

\section{PENDAHULUAN}

Menurut Kunandar (2007) salah satu faktor utama yang menentukan mutu pendidikan adalah guru. Seorang guru bukan hanya memberikan pengetahuan kepada siswa dengan langsung tetapi guru harus punya perencanaan yang baik agar pembelajaran yang akan dilaksanakan berjalan dengan baik dan tujuan pembelajaran dapat dicapai dengan baik juga. Media merupakan bagian yang integral dari keseluruhan situasi mengajar, sehingga media merupakan salah satu unsur yang harus dikembangkan guru untuk membantu mempertinggi mutu belajar mengajar.

Seiring dengan berkembangnya zaman banyak sekali alat-alat media yang dapat digunakan sebagai media dalam pembelajaran, tapi sangat disayangkan mengapa sebagian besar dari pendidik dan yang mendidik kurang faham betul akan media, seperti contoh: sebagian besar guru menganggap semua alat adalah media padahal apabila alat itu belum memberikan informasi alat itu belum disebut media ini adalah salah satu yang sangat kecil tapi jarang di perhatikan oleh para pendidik. 
Selain itu banyak sekali yang belum mengetahui manfat-manfaat dari media pembelajaran, dan tidak banyak pula bagi pendidik yang kurang bisa memilih media yang efekti dan menyenangkan bagi proses pembelajaran, Peran guru dalam inovasi dan pengembangan media pengajaran sangat diperlukan mengingat guru dapat dikatakan sebagai pemain yang sangat berperan dalam proses belajar mengajar di kelas, yang hendaknya dapat mengolah kemampuannya untuk membuat media pengajaran lebih efektif dan efisien.

Hal ini, menurut Wijaya dkk (1991:2),ternyata masih banyak kekurang pahaman bagi pendidik mengenai media pembelajaran dan disini mungkin akan dijelaskan bagaimana sih memilih media yang efektif dan menyenangkan bagi proses pembelajaran dan apa saja manfaatmanfat media pembelajaran. Sejalan dengan pendapat di atas, Miarso (1986:105) menyatakan bahwa hal pertama yang harus dilakukan guru dalam penggunaan media secara efektif adalah mencari, menemukan, dan memilih media yang memenuhi kebutuhan belajar anak, menarik minat anak, sesuai dengan perkembangan kematangan dan pengalamannya serta karakteristik khusus yang ada pada kelompok belajarnya. Karaketristik ini antara lain adalah kematangan anak dan latar belakang pengalamannya serta kondisi mental yang berhubungan dengan usia perkembangannya.

Selain masalah ketertarikan siswa terhadap media, keterwakilan pesan yang disampaikan guru juga hendaknya dipertimbangkan dalam pemilihan media. Setidaknya ada tiga fungsi yang bergerak bersama dalam keberadaan media. Pertama, fungsi stimulasi yang menimbulkan ketertarikan untuk mempelajari dan mengetahui lebih lanjut segala hal yang ada pada media. Kedua, fungsi mediasi yang merupakan perantara antara guru dan siswa. Dalam hal ini, media menjembatani komunikasi antara guru dan siswa. Ketiga, fungsi informasi yang menampilkan penjelasan yang ingin disampaikan guru. Dengan keberadaan media, siswa dapat menangkap keterangan atau penjelasan yang dibutuhkannya atau yang ingin disampaikan oleh guru.

Pada materi sistem pencernaan manusia, selama ini media pembelajaran yang digunakan lebih banyak gambar 2 dimensi berupa charta, torso, video pembelajaran, dan power point. Kelebihan dan kekurangan pasti ada pada setiap jenis media pembelajaran sistem pencernaan tersebut. Misalnya jika media berupa gambar, maka siswa akan cenderung lupa setelah diberikan soal, jika berupa torso organ, disamping mahal harganya juga terkesan ribet yaitu harus memindah dari laboratorium ke kelas. Jika berupa video flash dan power point, maka seorang guru tentunya dituntut untuk bisa menguasai teknologi komputer dalam pengoperasiannya.

Nah, untuk mengantisipasi beberapa kekurangan tersebut, perlu dicari alternatif media pembelajaran pencernaan yang relatif mudah dibuat siapapun, dengan biaya murah bahkan bisa menggunakan barang bekas, dan yang paling penting mengena atau tepat sasaran. Oleh karena itu, penulis merasa perlu untuk membuat media pembelajaran alternatif yang mudah, murah dan efisien, dengan judul "Pemanfaatan Celemek Sebagai Media Pembelajaran Sistem Pencernaan Manusia".

\section{METODE PENELITIAN}

\section{Jenis dan Konsep Dasar}

Jenis inovasi yang dikembangkan adalah sebuah alat peraga berupa Celemek (kain yang dipakai untuk mencegah baju kotor saat memasak dengan cara dikalungkan) yang diberi gambar organ pencernaan manusia mulai dari kerongkongan - anus. sehingga membuat seluruh siswa mudah dalam menguasai materi pelajaran karena merasa seperti organ tubuh sendiri. 


\section{INTELIGENSI: Jurnal Ilmu Pendidikan}

Konsep dasar penyusunan media evaluasi ini adalah adanya berbagai media pembelajaran sistem pencernaan manusia yang sudah umum seperti power point, video flash, torso dan buku paket. Maka kemudian penulis berpikir, bagaimana jika gambar organ pencernaan manusia ditempelkan di tubuh, karena sejatinya organ pencernaan manusia termasuk organ dalam yang tidak bisa dilihat dengan kasat mata.

\section{Definisi Kerja Operasional}

Celemek sistem pencernaan adalah sebuah media pembelajaran yang bertujuan memberikan gambaran kepada siswa tentang organ penyusun sistem pencernaan manusia terutama organ dalam seperti kerongkongan, lambung, usus, pankreas, hati, rektum dan anus. Dengan media celemek yang berisi gambar organ pencernaan, siswa seolah dapat melihat letak dan nama organ pencernaan beserta fungsinya, bahkan bisa mengetahui proses pencernaan makanan itu sendiri.

\section{Proses Pembaharuan}

Proses KBM materi sistem pencernaan selama ini seringkali memakai media power point, video flash, torso dan gambar. Hanya saja penulis menilai itu sudah biasa, dan perlu pengembangan media alternatif yang mudah, murah dan sederhana. Gambar organ pencernaan jika ditempelkan pada tubuh, seolah-olah siswa melihat langsung organ pencernaannya masing. Dari situ tercetuslah ide untuk membuat clemek yang digambar organ pencernaan dalam, lalu dipakai guru saat mengajar di depan kelas.

Adapun bahan yang dibutuhkan untuk membuat media celemek yaitu :

a. Banner bekas ukuran $45 \mathrm{~cm}$ x $20 \mathrm{~cm}$.

b. Spidol boardmarker permanen hitam

c. Tali rafia

d. Spidol warna

e. Gunting

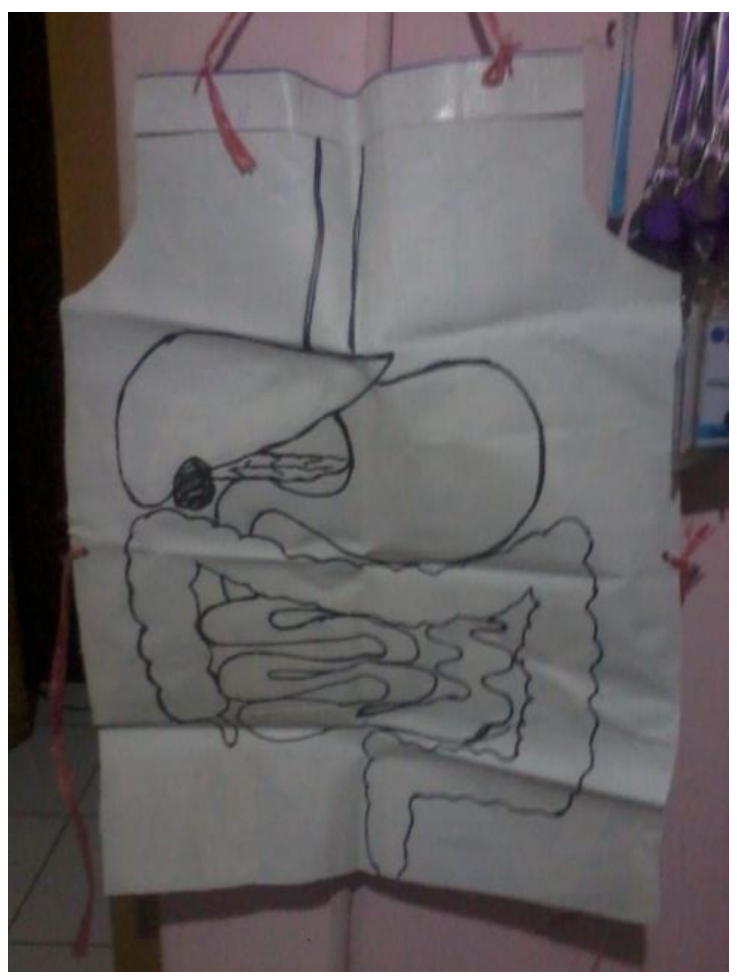

Foto 1. Celemek Bergambar organ pencernaan manusia

\section{Aplikasi Praktis dalam Pembelajaran}

Agar pemanfaatan media pembelajaran yang penulis buat bisa dirasakan manfaatnya dalam proses KBM, maka selanjutnya penulis aplikasikan dalam pembelajaran. Langkah-langkah penggunaan media celemek dalam pembelajaran sistem pencernaan manusia adalah sebagai berikut :

1. Guru membuka pelajaran dengan salam, selanjutnya memeriksa kehadiran siswa.(foto 2. terlampir)

2. Guru memberikan apersepsi dengan menanyakan bagaimana bisa makanan yang kita konsumsi tidak sama setelah keluar dari tubuh?bagaimana prosesnya? (foto 3. terlampir).

3. Berdasarkan jawaban siswa yang beragam, lalu penulis menjelaskan tujuan pembelajaran hari itu yaitu tentang organ dan proses pencernaan makanan.

4. Awalnya siswa kesulitan dalam memberikan tanggapan tentang proses pencernaan makanan. 
5. Selanjutnya untuk mengingatkan siswa akan macam organ pencernaan dan letaknya dalam tubuh, penulis memakai celemek sistem pencernaan manusia dan mulai menjelaskan nama, urutan, dan proses pencernaan makanan dalam tubuh. (foto 4 . terlampir)

6. Siswa melakukan diskusi kelompok dan guru memberikan LKS bergambar.(foto 5. terlampir)

7. Siswa diberi soal evaluasi.

\section{HASIL DAN PEMBAHASAN}

Sesuai dengan tujuan dari pembuatan media pembelajaran ini, yaitu untuk membuat rancangan media pembelajaran, maka media tersebut diaplikasikan dalam proses pembelajaran.

\section{Data hasil aplikasi media pembelajaran dalam KBM}

Tabel 1. Nilai pre-test Sebelum penggunaan media celemek sistem pencernaan

\begin{tabular}{|c|c|c|}
\hline Kriteria & $\begin{array}{c}\text { Jumlah } \\
\text { siswa }\end{array}$ & Prosentase \\
\hline Tuntas & 6 & $27,27 \%$ \\
\hline Tidak Tuntas & 16 & $72,73 \%$ \\
\hline Total siswa & $\mathbf{2 2}$ & $\mathbf{1 0 0 \%}$ \\
\hline
\end{tabular}

Keterangan : jika siswa mendapat nilai $\geq$ 75, maka dikatakan tuntas. Karena KKM (kriteria ketuntasan minimal) $I P A=75$.

Tabel 2. Nilai ulangan harian setelah penggunaan media celemek sistem pencernaan

\begin{tabular}{|c|c|c|}
\hline Kriteria & $\begin{array}{c}\text { Jumlah } \\
\text { siswa }\end{array}$ & $\begin{array}{c}\text { Prosentas } \\
\text { e }\end{array}$ \\
\hline Tuntas & 21 & $95,45 \%$ \\
\hline $\begin{array}{c}\text { Tidak } \\
\text { Tuntas }\end{array}$ & 1 & $4,55 \%$ \\
\hline $\begin{array}{c}\text { Total } \\
\text { siswa }\end{array}$ & $\mathbf{2 2}$ & $\mathbf{1 0 0 \%}$ \\
\hline
\end{tabular}

Keterangan : jika siswa mendapat nilai $\geq$ 75, maka dikatakan tuntas. Karena KKM (kriteria ketuntasan minimal) IPA $=75$.
Tabel 3. Tabulasi nilai siswa sebelum dan sesudah penggunaan Celemek Sistem

Pencernaan Manusia

\begin{tabular}{|c|c|c|}
\hline \multirow{2}{*}{ Kriteria } & \multicolumn{2}{|c|}{ Hasil belajar siswa } \\
\cline { 2 - 3 } & Pretest & $\begin{array}{c}\text { Ulangan } \\
\text { harian }\end{array}$ \\
\hline Tuntas & $\begin{array}{c}6 \\
(27,27 \%)\end{array}$ & $\begin{array}{c}21 \\
(95,45 \%)\end{array}$ \\
\hline Tidak & $\begin{array}{c}16 \\
\text { tuntas }\end{array}$ & $1(4,55 \%)$ \\
\hline Jumlah & $\begin{array}{c}\mathbf{2 2} \\
(\mathbf{1 0 0} \%)\end{array}$ & $\mathbf{2 2}(\mathbf{1 0 0 \% )}$ \\
\hline
\end{tabular}

Keterangan : jika siswa mendapat nilai $\geq$ 75, maka dikatakan tuntas. Karena KKM (kriteria ketuntasan minimal) $I P A=75$.

\section{Pembahasan hasil aplikasi media pembelajaran dalam KBM}

Sebelum pembelajaran, untuk mengetahui sejauh mana pengetahuan siswa tentang materi pencernaan, terlebih dahulu diberi soal pre-test dengan asumsi pada saat tingkat Sekolah Dasar (SD) siswa sudah pernah menerima materi tentang Sistem Pencernaan Makanan. Hasilnya (lihat tabel 1.) dari 22 orang siswa, 6 orang siswa diantaranya mempunyai nilai $\geq 75$, sedangkan sebanyak 16 orang siswa mempunyai nilai $\leq 75$. Ketika guru mengkonfirmasi kendala apa yang dihadapi, bukankah waktu SD sudah mempelajari materi sistem pencernaan makanan, sebagian besar mengatakan lupa karena sudah beberapa tahun sebelumnya mempelajari. Padahal seharusnya, dasar pengetahuan yang sudah pernah dimiliki oleh siswa, seharusnya menjadi modal bagi siswa untuk bisa lebih memahami materi yang sama, yang sebenarnya hanya pengembangan dari materi Pencernaan saat SD.

Setelah aplikasi penggunaan celemek sebagai media pembelajaran sistem pencernaan manusia, dapat meningkatkan hasil belajar siswa. Hasilnya (lihat tabel 2.) 21 orang siswa mempunyai nilai $\geq 75$, hanya 1 siswa yang mempunyai nilai $\leq 75$. Artinya ketuntasan siswa semakin tinggi setelah menggunakan media celemek pada 
materi sistem pencernaan manusia. Karena siswa menjadi semakin memahami, bahwa organ pencernaan yang ditunjukkan oleh media celemek, sama persis dengan yang ada di dalam tubuh manusia dari sisi letak dan fungsinya. Hal ini sejalan dengan Ely (dalam Danim, 1994:13) menyebutkan manfaat media dalam pengajaran adalah sebagai berikut :

a. Meningkatkan mutu pendidikan dengan cara meningkatkan kecepatan belajar (rate of learning).

b. Memberi kemungkinan pendidikan yang sifatnya lebih individual dengan jalan memperkecil atau mengurangi kontrol guru yang tradisional dan kaku, memberi kesempatan luas kepada anak untuk berkembang menurut kemampuannya serta memungkinkan mereka belajar menurut cara yang dikehendakinya.

c. Memberi dasar pengajaran yang lebih ilmiah pada siswa.

d. Pengajaran dapat dilakukan secara mantap karena meningkatnya kemampuan manusia untuk memanfaatkan media komunikasi, informasi dan data secara lebih konkrit dan rasional.

e. Meningkatkan terwujudnya kedekatan belajar (immediacy learning) karena media pengajaran dapat menghilangkan atau mengurangi jurang pemisah antara kenyataan di luar kelas dan di dalam kelas serta memberikan pengetahuan langsung.

Hal senada juga disampaikan oleh Arsyad (2013: 74) yang menjelaskan bahwa kriteria pemilihan media bersumber dari konsep bahwa media pembelajaran merupakan bagian dari sistem instruksional secara keseluruhan. Dengan demikian peningkatan hasil ulangan harian siswa, semakin memperkuat keyakinan penulis, bahwa media pembelajaran yang sederhana ternyata juga bisa meningkatkan pemahaman siswa pada materi yang diajarkan, dalam hal ini materi Sistem

\section{Pencernaan Manusia (lihat tabel 3.)}

\section{KESIMPULAN DAN SARAN Kesimpulan}

Berdasarkan hasil praktek dan pengamatan guru dapat disimpulkan sebagai berikut:

1. Pembuatan media pembelajaran celemek sistem pencernaan manusia ternyata sangat mudah dan bisa dibuat oleh siapapun, dengan biaya yang murah, dan sederhana.

2. Media celemek dapat meningkatkan aktivitas sekaligus hasil belajar siswa sistem pencernaan manusia, yaitu dilihat dari hasil ulangan yang mencapai 95,45\% (21 orang) dari 22 siswa.

3. Dengan memanfaatkan barang bekas yang ada di sekitar kita, akan membuat pendidik semakin kreatif dalam membuat media pembelajaran.

\section{Saran}

Mengingat besarnya manfaat karya inovasi pembelajaran berupa media celemek, dapat diberikan saran sebagai berikut :

1. Media celemek hendaknya diaplikasikan pada materi lain yang menjelaskan tentang organ dalam manusia seperti sistem pernapasan, sistem ekskresi dan sistem reproduksi manusia.

2. Perlunya penambahan warna pada media celemek sesuai dengan warna organ agar lebih menarik.

\section{DAFTAR PUSTAKA}

Arsyad, Azhar. 2013. Media

Pembelajaran. Jakarta: Rajawali

Press

Danim, Sudarwan. 1995. Media

Komunikasi Pendidikan. Jakarta:

Bumi Aksara.

Kunandar. 2007. Guru Profesional implementasi Kurikulum Tingkat Satuan Pendidikan (KTSP) dan 


\section{INTELIGENSI: Jurnal Ilmu Pendidikan | 2018-1}

Persiapan menghadapi Sertifikasi

Guru. Jakarta: PT.Grafindo Persada.

Miarso, Yusufhadi. dkk. 1986. Media

Pendidikan. Jakarta: Rajawali.

Rahardjo, R. 1986. Media

Pembelajaran. Jakarta: Rajawali.
Wijaya, Cece. dkk. 1991. Upaya Pembaharuan dalam Pendidikan dan Pengajaran. Bandung: Remaja Rosdakarya 


\section{INTELIGENSI: Jurnal Ilmu Pendidikan $\mid$ 2018-1}

\section{Lampiran 1.}

\section{FOTO KEGIATAN APLIKASI PEMANFAATAN CELEMEK SEBAGAI MEDIA PEMBELAJARAN SISTEM PENCERNAAN MANUSIA DALAM KBM}

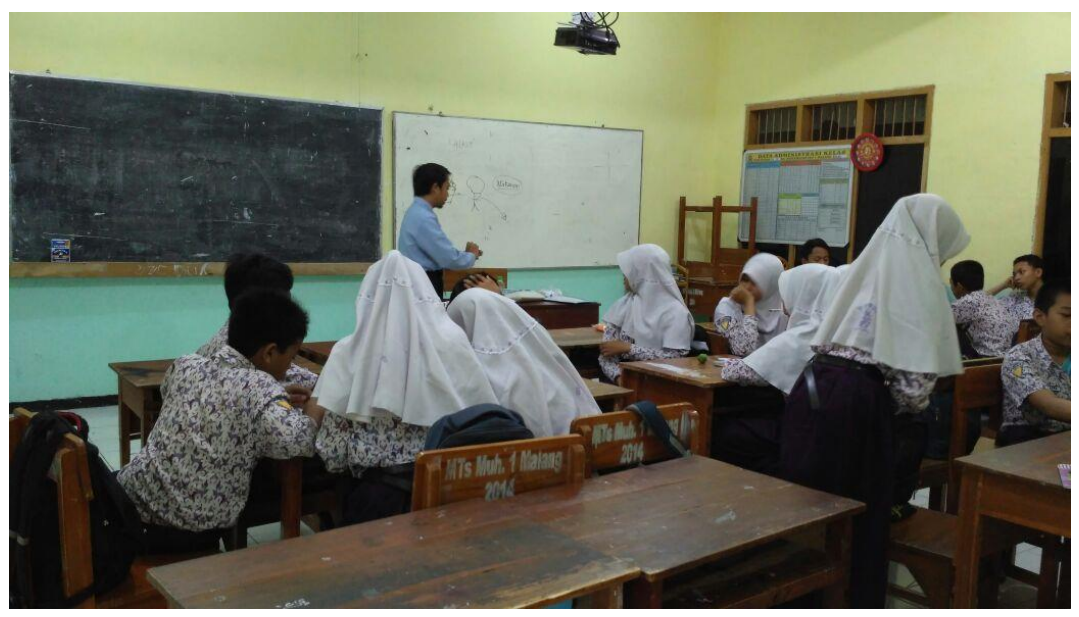

Foto 2. Kegiatan Pendahuluan,memeriksa kehadiran
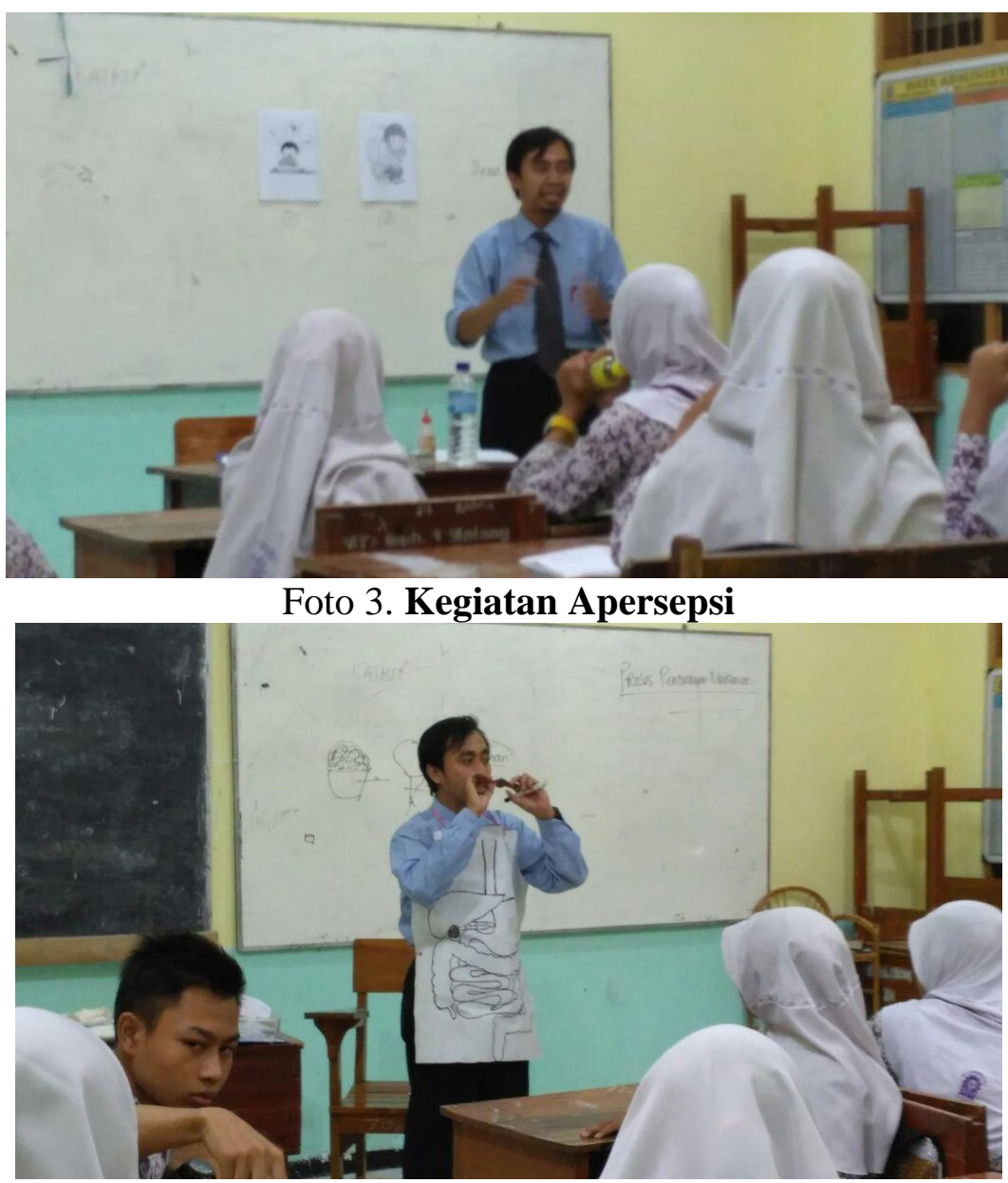

Foto 4a. Penggunaan media celemek 


\section{INTELIGENSI: Jurnal Ilmu Pendidikan |2018-1}

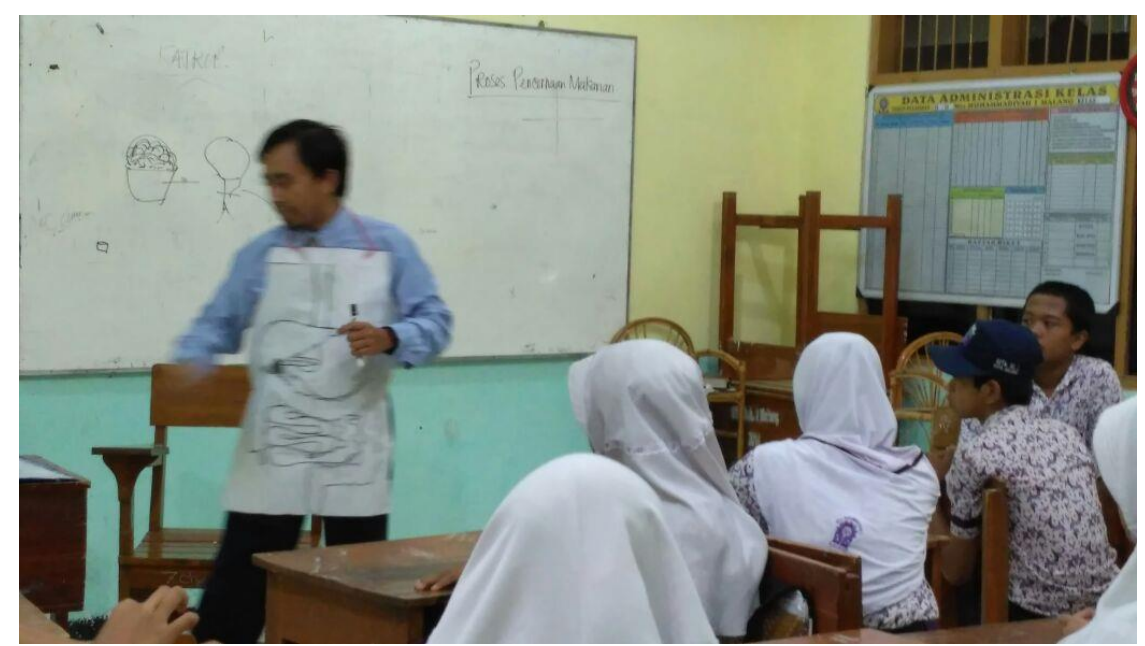

Foto 4b. Penggunaan media celemek

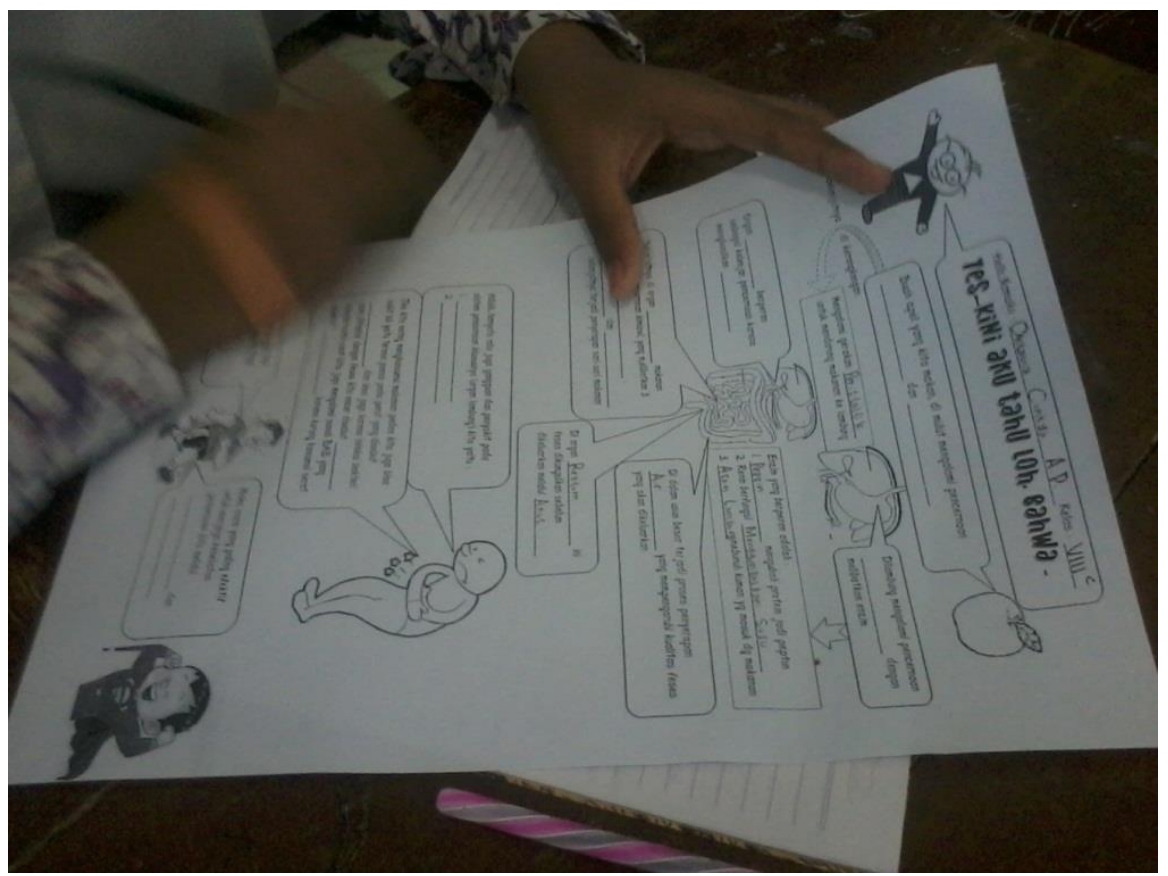

Foto 5. LKS bergambar untuk menunjang KBM 